\title{
Pulmonary haemodynamics after surfactant replacement in severe neonatal respiratory distress syndrome
}

\author{
M-C Bloom, M Roques-Gineste, F Fries, M-C Lelong-Tissier
}

Service de Médicine Infantile B, Hôpital Purpan, Place du Docteur, Baylac, 31059 Toulouse, Cédex, France M-C Bloom $M$ Roques-Gineste F Fries

M-C Lelong-Tissier

Correspondence to: Dr Bloom.

Accepted 17 May 1995

\begin{abstract}
Aortopulmonary pressure difference and pulmonary blood flow velocity were studied during the first 48 hours of life in 12 premature neonates with severe respiratory distress syndrome (RDS), treated by natural surfactant, and in 25 premature neonates with mild RDS. A non-invasive Doppler ultrasound method was used to estimate aortopulmonary pressure difference and pulmonary blood flow velocity from the left pulmonary artery. Aortopulmonary pressure difference was significantly lower at 6 hours of age in the infants with severe RDS and was not increased one hour after surfactant therapy. Aortopulmonary gradient started to rise at 24 hours of age and was equal to that of neonates with mild RDS at 48 hours. Pulmonary blood flow velocity was significantly lower, initially in the severe RDS group, and was not increased one hour after surfactant therapy. Left pulmonary artery flow velocity began to rise after 24 hours and reached the
\end{abstract}
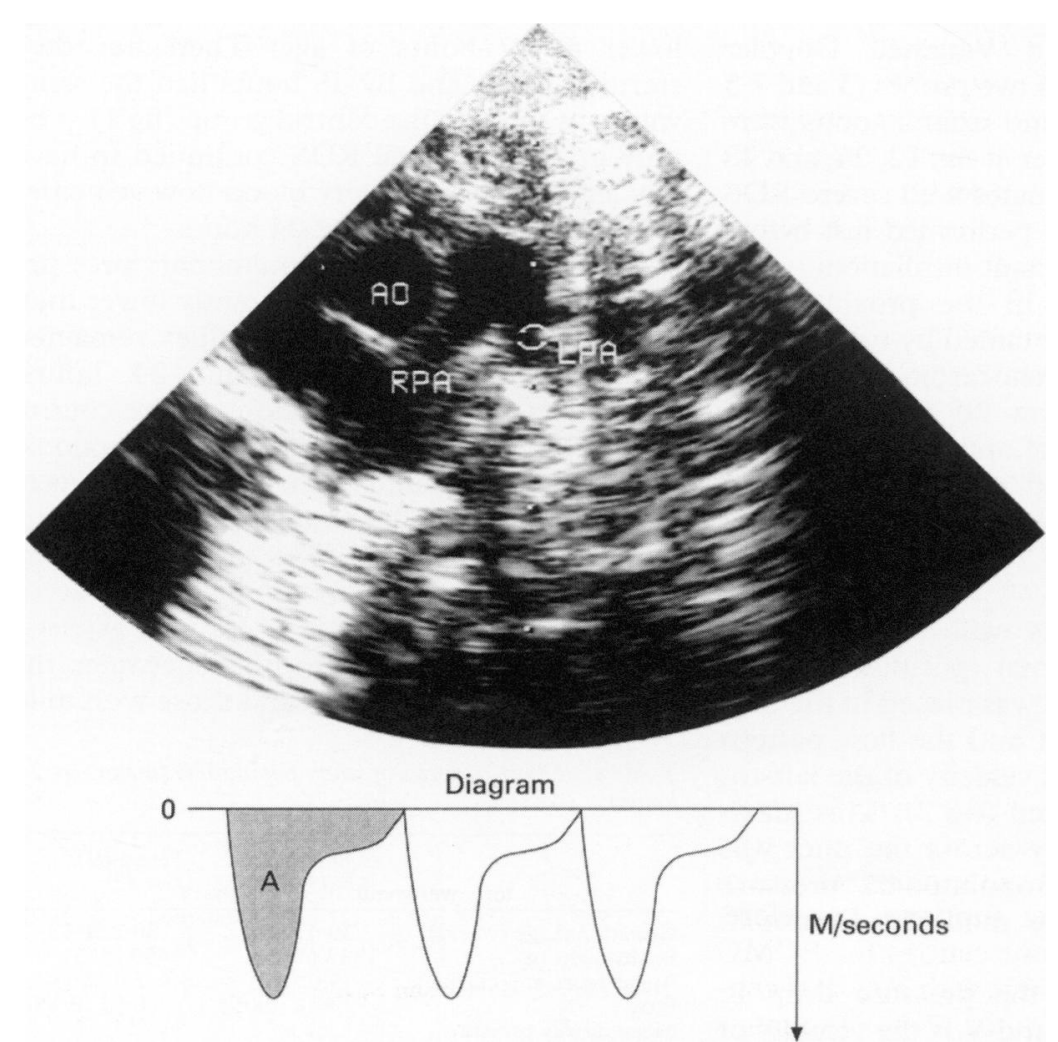

Figure 1 Visualisation of sample site in the proximal left pulmonary artery (LPA). The area under the velocity curve $(A)$ represents the left pulmonary artery velocity time integral on the diagram. Aorta (AO); right pulmonary artery (RPA). values of the mild RDS group at 48 hours.

These data indicate that aortopulmonary pressure difference and pulmonary blood flow are low in the acute phase of RDS and that surfactant treatment does not seem to affect these values.

(Arch Dis Child 1995; 73: F95-F98)

Keywords: Doppler ultrasound, pulmonary blood flow velocity, aortopulmonary pressure, respiratory distress syndrome.

Whether pulmonary arterial pressure is correlated with the severity of hyaline membrane disease remains a matter of controversy. ${ }^{1-5}$ Intratracheal instillation of exogenous surfactant improves rapidly oxygenation in premature neonates with hyaline membrane disease. ${ }^{6-8}$

Various studies have evaluated pulmonary haemodynamics after surfactant replacement in preterm animals ${ }^{910}$ and infants, ${ }^{13411}$ with contradictory results, but they either only determined immediate effects ${ }^{411}$ or did not differentiate the severity of hyaline membrane disease. This study aimed to define the evolution of aortopulmonary gradient and pulmonary blood flow throughout the acute phase of the illness in preterm infants with severe respiratory distress syndrome (RDS) treated with surfactant. These data were compared with those obtained from ventilated premature neonates with no or only mild RDS.

\section{Method}

The study population consisted of 37 premature neonates admitted to the neonatal intensive care unit. All patients underwent intubation and ventilation with a pressure controlled ventilator (Babylog 8000; Dräger, Germany).

Twelve infants entering the study had severe RDS, the severity of which was assessed by fraction of inspired oxygen $\left(\mathrm{FIO}_{2}\right)$ of $>60 \%$ and an oxygenation index (OI) of $>18$ (OI: mean airway pressure (MAP) above atmosphere $\times \mathrm{FIO}_{2} \times 100$, divided by postductal $\mathrm{PaO}_{2}(\mathrm{~mm} \mathrm{Hg})$ ). All 12 patients received a dose $(2.5 \mathrm{ml} / \mathrm{kg})$ of natural surfactant (Curosurf, Serono) by intratracheal instillation, between 2 and 16 hours of age. Subsequent ventilatory management consisted of an initial reduction in $\mathrm{FIO}_{2}$ followed by sequential reduction of inspiratory pressure, frequency, inspiratory:expiratory time ratio and positive end expiratory pressure (PEEP). 

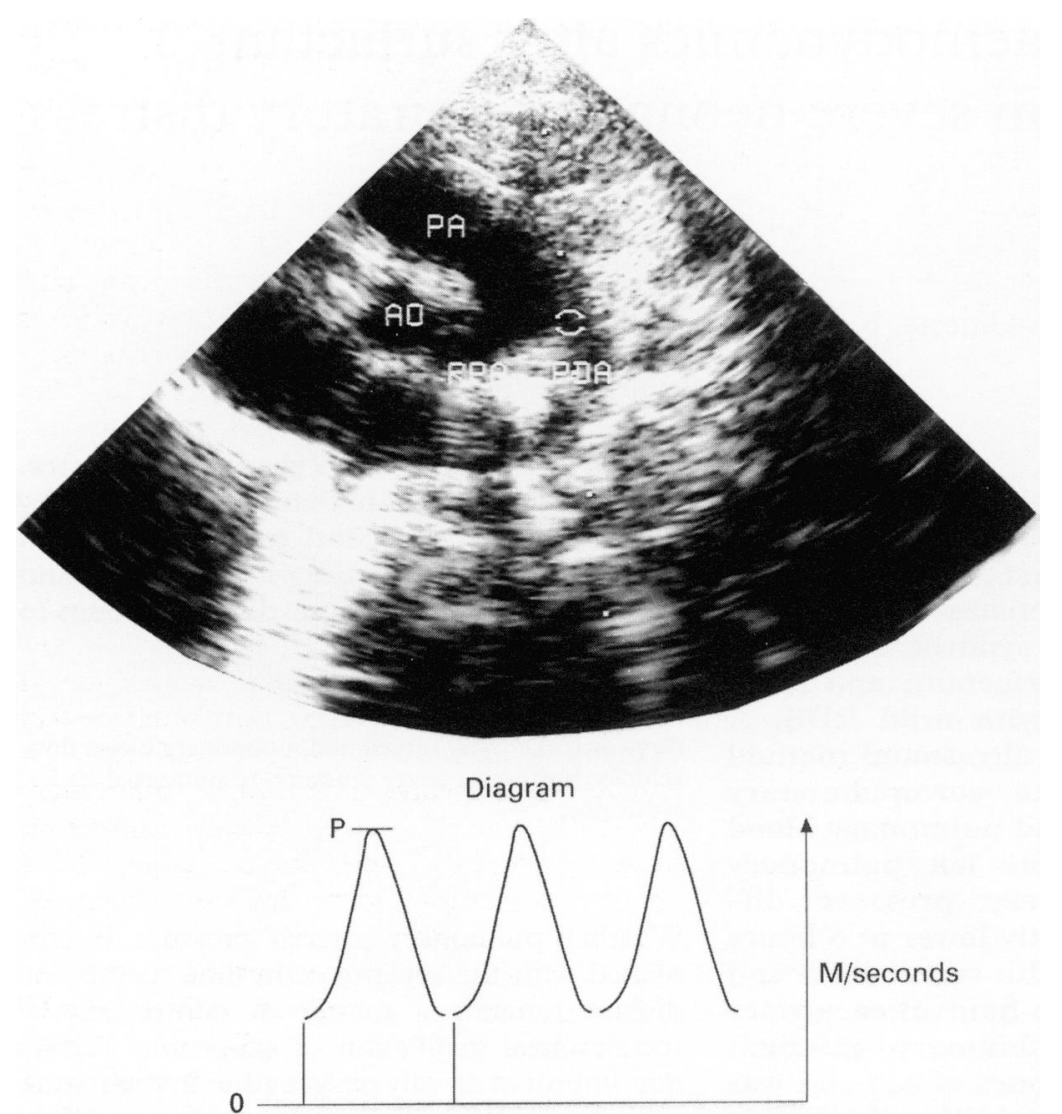

Figure 2 The sample site indicates the measuring point for the aortopulmonary pressure difference in the patient ductus arteriosus (PDA). Maximum peak velocity of the left-to-right shunt is shown as $(P)$ on the diagram. Main pulmonary artery $=P A$. throughout the cardiac cycle, or with a mild degree of right-to-left ductal shunting (under $20 \%$ ); or balanced bidirectional flow with important right-to-left shunting in systole.

At the same time as the Doppler measurements, systemic artery pressure (SAP) was measured using an indwelling umbilical arterial catheter or Dynamap. The pulmonary arterial pressure (PAP) was derived from systolic aortic pressure minus the aortopulmonary pressure difference.

Results are reported as means (SD). Differences between paired data were analysed using Student's paired $t$ test and unpaired data using the unpaired $t$ test. A P value of $<0.05$ was regarded as significant.

\section{Results}

The infants with severe RDS treated with surfactant and the control infants had similar gestational ages, birthweights, and Apgar scores at 5 minutes. $\mathrm{FIO}_{2}, \mathrm{MAP}$, and $\mathrm{OI}$ were significantly higher in the severe RDS group on admission to the neonatal intensive care (table 1).

There were no significant differences in mean aortopulmonary pressure difference and left pulmonary artery blood flow velocity before or after surfactant therapy in the severe RDS group, but surfactant administration significantly decreased $\mathrm{FIO}_{2}, \mathrm{MAP}$, and $\mathrm{OI}$ (table 2). There was no significant difference in systolic systemic pressure before or after surfactant treatment (table 2).

Mean left pulmonary artery blood flow velocities in neonates with severe RDS were significantly lower than in the control group at 6 hours of age. These remained significantly lower at 12 hours of age. Thereafter they started to rise, and by 48 hours had the same values as those in the control group (fig 1 ). The only infant with fatal RDS continued to have low left pulmonary artery blood flow velocities until he died at the age of 24 hours.

At 6 hours of age, aortopulmonary pressure difference values were significantly lower than in the control group. These values remained significantly lower at 12 and 24 hours. Thereafter, they reached those of the control group by 48 hours. Balanced bidirectional ductal flow was found in six infants with severe RDS at 6 hours of age, but was not seen in the control group (fig 2). The infant with fatal RDS maintained a bidirectionnal shunt at 24 hours.

Systolic SAP did not differ between the neonates with severe RDS and those with mild

Table 1 Characteristics of study population (mean age 2 hours)

\begin{tabular}{lcc}
\hline & $\begin{array}{l}\text { Control group } \\
(n=25)\end{array}$ & $\begin{array}{l}\text { Severe RDS } \\
(n=12)\end{array}$ \\
\hline Gestational age (weeks) & $30 \cdot 4(0 \cdot 2)$ & $30 \cdot 2(1 \cdot 3)$ \\
Birthweight (g) & $1333(188)$ & $1400(235)$ \\
Apgar score at 5 minutes & $9 \cdot 0(1 \cdot 3)$ & $7 \cdot 0(2 \cdot 1)$ \\
FIO & $0 \cdot 24(0 \cdot 05)$ & $0 \cdot 85(0 \cdot 15)^{\star}$ \\
$\mathrm{Mean}_{2}$ airway pressure & $6 \cdot 4(2 \cdot 1)$ & $12 \cdot 8(2 \cdot 1)^{\star}$ \\
$\quad$ (cm $\left.\mathrm{H}_{2} \mathrm{O}\right)$ & $2 \cdot 7(1 \cdot 3)$ & $20 \cdot 6(2 \cdot 8)^{\star}$ \\
Oxygenation index & &
\end{tabular}

$\star P<0.05$ versus control values. 
Table 2 Effects of surfactant in severe RDS before and one hour after treatment (mean age 7 hours)

\begin{tabular}{|c|c|c|c|}
\hline & Before & After & Control group \\
\hline $\begin{array}{l}\mathrm{FIO}_{2} \\
\text { Mean airway pressure }\left(\mathrm{cm} \mathrm{H}_{2} \mathrm{O}\right) \\
\text { OI } \\
\text { VTI LPA } \\
\text { Aortopulmonary difference }(\mathrm{mm} \mathrm{Hg}) \\
\text { SAP }(\mathrm{mm} \mathrm{Hg}) \\
\mathrm{PaCO}_{2}(\mathrm{~mm} \mathrm{Hg})\end{array}$ & $\begin{array}{l}0 \cdot 89(0 \cdot 14) \\
12 \cdot 75(2 \cdot 5) \\
22 \cdot 3(5 \cdot 9) \\
10 \cdot 7(1 \cdot 6) \\
1 \cdot 9(3 \cdot 0) \\
45 \cdot 0(6 \cdot 3) \\
41 \cdot 3(14 \cdot 2)\end{array}$ & $\begin{array}{l}0 \cdot 45(0 \cdot 24)^{\star} \\
10 \cdot 6(3 \cdot 2)^{\star} \\
10 \cdot 0(9 \cdot 0)^{\star} \\
11 \cdot 3(2 \cdot 6) \\
4 \cdot 6(3 \cdot 9) \\
44 \cdot 0(5 \cdot 7) \\
40 \cdot 2(6 \cdot 7)\end{array}$ & $\begin{array}{l}0 \cdot 26(0 \cdot 14) \\
6 \cdot 2(1 \cdot 6) \\
2 \cdot 6(1 \cdot 5) \\
13 \cdot 5(1 \cdot 8) \\
6 \cdot 8(3 \cdot 3) \\
46 \cdot 3(6 \cdot 8) \\
40 \cdot 5(4 \cdot 6)\end{array}$ \\
\hline
\end{tabular}

$\star \mathrm{P}<0.05 v$ values before surfactant.

RDS at 6 hours of age. SAP increased with age in the control group. In neonates with severe RDS the values were significantly lower at 12 and 24 hours of age. They reached those of the control group by 48 hours.

A comparison between the two groups is shown in table 3. Systolic pulmonary arterial pressure is derived from systolic systemic blood pressure minus the aortopulmonary pressure difference.

Pulmonary arterial pressure decreased with age in both groups and did not differ significantly between the patients with severe and mild RDS.

The pulmonary:systemic arterial pressure ratio (PAP:SAP) was significantly higher in the neonates with severe RDS than in the controls at 6,12 , and 24 hours of age.

\section{Discussion}

We found that pulmonary blood flow was reduced with a low aortopulmonary difference during the first 48 hours in premature neonates with severe RDS despite treatment with natural porcine surfactant and a decrease in OI. These findings agree with those of a previous study of severe RDS using the same methods. ${ }^{3}$ Left pulmonary artery flow might be low because of low right ventricular output as well as high pulmonary arterial pressures with right-to-left extra-pulmonary shunting in preterm infants with severe RDS.

Aortopulmonary pressure differences were low, suggesting that neonates with severe RDS maintain near normal systemic pulmonary arterial pressures for the first two days.

Half of our patients with severe RDS had balanced bidirectional shunts, which are seen when pulmonary arterial pressures are the same or slightly lower than aortic pressures. ${ }^{14}$ On the other hand, our results showed that there was a delay in the normal postnatal rise in systemic blood pressure in the severe form of neonatal RDS, maintaining a low gradient across the arterial duct.

The most striking finding of this study is the significant difference between neonates with severe and those with mild RDS. In the acute phase of hyaline membrane disease premature neonates with severe RDS had lower values of aortopulmonary gradient and pulmonary blood flow velocities than those of ventilated neonates with mild RDS. We did not find any balanced bidirectional shunt in premature neonates with mild RDS. Bidirectional flow is common in healthy premature neonates. ${ }^{12}$ The explanation for this may be twofold. On the one hand, we did not include those patients in whom the left-to-right component largely dominated the cardiac cycle. On the other hand, we think that the positioning of the sampling site is critical. The maximum left-toright blood flow velocity changes as the Doppler cell moves from one end of the ductus arteriosus to the other. Our measurements were taken near the main pulmonary artery ostium where left-to-right velocity is maximal. ${ }^{13}$ Initially, at 6 hours, pulmonary blood flow and aortopulmonary difference were significantly lower in the severe RDS group with much more frequent balanced bidirectional shunt.

Systolic systemic arterial pressure did not differ significantly. Consequently, the PAP:SAP ratio was higher. Previous studies ${ }^{1251516}$ have shown that there is a delay in the normal postnatal fall in pulmonary arterial pressure in RDS. Our data agree with these findings, showing that aortopulmonary gradient and systemic pressure were significantly lower in the severe RDS group at 12 and 24 hours and that there was a slower decrease in the PAP:SAP ratio.

We found no difference in the calculated pulmonary arterial pressure between the two groups. Systemic blood pressure was significantly lower at 12 and 24 hours in the severe RDS group, suggesting that systemic hypotension and myocardial dysfunction are partly responsible for the low pulmonary blood flow and aortopulmonary gradient. ${ }^{2}$

In the first few hours patients with severe RDS may have low pulmonary perfusion that is probably associated with persistent pulmonary hypertension. Subsequently, systemic hypotension associated with low cardiac output and high ventilation might predominate and cause the delay in the normal neonatal circulatory transition.

In our study neonates with severe RDS all received natural surfactant. We were able to compare their data with those obtained from similar infants without surfactant administration, but our data have suggested that administration of natural surfactant did not reduce pulmonary resistance, with no increase in

Table 3 Comparison of systemic and pulmonary artery pressures in neonates with severe and mild RDS

\begin{tabular}{|c|c|c|c|c|c|c|c|c|}
\hline \multirow{2}{*}{$\begin{array}{l}\text { Age } \\
\text { (hours) }\end{array}$} & \multicolumn{4}{|c|}{ Control group } & \multicolumn{4}{|l|}{ Severe RDS } \\
\hline & $S A P$ & $A P$ difference & $P A P$ & $P A P: S A P$ & $S A P$ & $A P$ difference & $P A P$ & $P A P: S A P$ \\
\hline $\begin{array}{r}6 \\
12 \\
24 \\
48\end{array}$ & $\begin{array}{l}45 \cdot 4(6 \cdot 7) \\
50 \cdot 5(4 \cdot 9) \\
52.9(5 \cdot 2) \\
57 \cdot 2(4.5)\end{array}$ & $\begin{array}{r}6 \cdot 8(3 \cdot 3) \\
14 \cdot 6(7 \cdot 0) \\
18 \cdot 9(4 \cdot 4) \\
24 \cdot 3(5 \cdot 1)\end{array}$ & $\begin{array}{l}36.8(6.8) \\
35.8(5.9) \\
34.0(7.0) \\
32.9(8.4)\end{array}$ & $\begin{array}{l}0.85(0.07) \\
0.71(0.13) \\
0.64(0.05) \\
0.55(0.1)\end{array}$ & $\begin{array}{l}44 \cdot 0(6 \cdot 6) \\
43 \cdot 6(6 \cdot 2) \\
45 \cdot 2(6 \cdot 0)^{\star} \\
53 \cdot 7(9 \cdot 0)\end{array}$ & $\begin{array}{r}1 \cdot 4(1 \cdot 6) \\
4 \cdot 2(3 \cdot 8) \\
9 \cdot 1(3 \cdot 8) \\
19 \cdot 9(6 \cdot 4)\end{array}$ & $\begin{array}{l}42 \cdot 6(6 \cdot 6) \\
39 \cdot 4(5 \cdot 8) \\
36 \cdot 2(8 \cdot 9) \\
33 \cdot 8(12 \cdot 0)\end{array}$ & $\begin{array}{l}0.96(0.04)^{\star} \\
0.88(0.09)^{\star} \\
0.8(0.1)^{\star} \\
0.66(0.11)\end{array}$ \\
\hline
\end{tabular}

${ }^{\star} \mathrm{P}<0.05 v$ control values. Systolic pulmonary artery pressure (PAP), systemic pressure (SAP), and their ratio (PAP:SAP), aortopulmonary pressure difference (AP difference). 


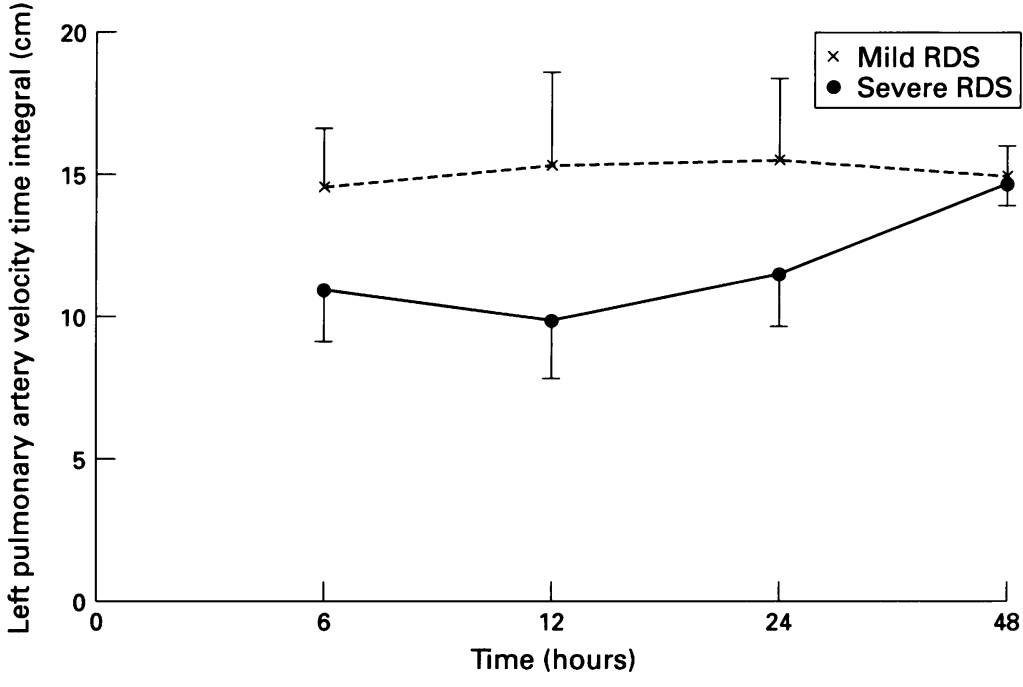

Figure 3 Left pulmonary artery velocity time integral values (centimetres, mean (SD)) from 6 hours until 48 hours of age in neonates with mild RDS and neonates with severe RDS treated by surfactant.

Figure 4 Aortopulmonary pressure differences (millimetres of mercury, mean (SD)) from 6 hours until 48 hours of age in neonates with mild RDS and neonates with severe $R D S$ treated by surfactant.

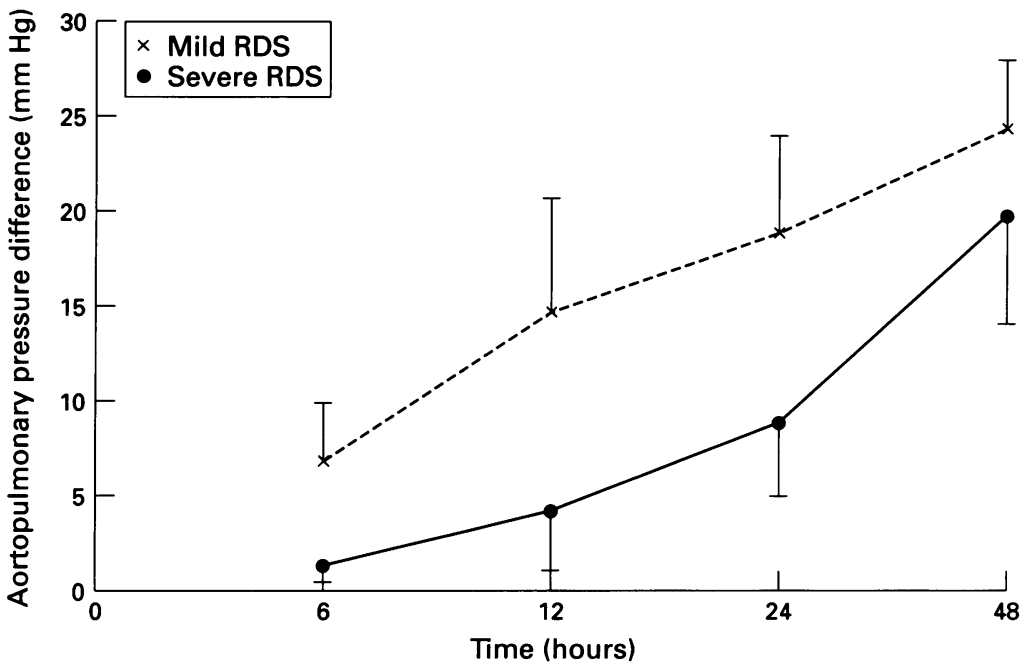

ratio, not by an immediate increase in pulmonary blood flow. ${ }^{4}$

Our observations have shown that all babies except one were clinically stable with PAP at systemic levels. Despite a low aortopulmonary gradient, pulmonary blood flow seemed adequate. Relative pulmonary hypertension does not automatically necessitate pharmacological intervention.

Low aortopulmonary difference and decreased left artery blood flow seem to be indicators of the severity of the RDS. ${ }^{17}$ They seem to be the result of a combination of relative pulmonary hypertension and myocardial dysfunction. They easily evaluate the course of circulatory transition in patients with severe RDS and may be of practical value in patient management. They are not modified by surfactant administration and we agree with other studies, that while relative high PAP is a feature of RDS, it is usually not necessary to treat it. We conclude that surfactant is not a vasodilator itself but acts only by improving pulmonary compliance, intrapulmonary shunting and the ventilation:perfusion ratio.

1 Evans NJ, Archer LNJ. Doppler assessment of pulmonary artery pressure and extrapulmonary shunting in the acute phase of hyaline membrane disease. Arch Dis Child 1991; 66: $6-11$.

2 Skinner JR, Boys RJ, Hunter S, Hey EN. Pulmonary and systemic arterial pressure in hyaline membrane disease. systemic arterial pressure in hyaln

3 Walther FJ, Benders MJ, Leighton JO. Persistent pulmonary hypertension in premature neonates with severe respiratory distress syndrome. Pediatrics 1992; 90: 899-904.

4 Halliday HL, McCord FB, McClure BG, Reid MMcC. Acute effects of instillation of surfactant in severe respiratory distress syndrome. Arch Dis Child 1989; 64: 13-6.

5 Seppanen MP, Kaapa P, Kero P, Saraste M. Dopplerderived systolic pulmonary artery pressure in acute neonatal respiratory distress syndrome. Pediatrics $1994 ; 93$. 769-73.

6 Hallman M, Merritt TA, Jarvenpaa AL, Boynton B, Mannino F, Gluck L, et al. Exogenous human surfactant for treatment of severe respiratory distress syndrome: a for treatment of severe respiratory distress syndrome: a 963-9.

7 Horbar JD, Soll RF, Sutherland JM, Kotagal U, Philip A, Kessler DL, et al. A multicenter randomized, placebocontrolled trial of surfactant therapy for respiratory distress syndrome. N Engl F Med 1989; 15: 959-65.

8 Raju TNK, Vidyasagar D, Bhat R, Sobel D, McCullouch $\mathrm{KM}$, Anderson $\mathrm{M}$, et al. Double-blind controlled trial of single-dose treatment with bovine surfactant in severe hyaline membrane disease. Lancet 1987; i: 651-6.

9 Vidyasagar D, Maeta H, Raju TNK, John E, Bhat R, Go M, et al. Bovine surfactant (surfactant TA) therapy in immature baboons with hyaline membrane disease. Pediatrics 1985; 75: 1132-42.

10 Clyman RI, Jobe A, Heymann M, Ikegami M, Roman C. Increased shunt through the patent ductus arteriosus after surfactant replacement therapy. ₹ Pediatr 1982; 100: 101-7.

11 Kaapa P, Seppanen M, Kero P, Saraste M. Pulmonary hemodynamics after synthetic surfactant replacement in nemodynamics after synthetic surfactant replacement in 123: $115-9$.

12 Hiraishi S, Horiguchi Y, Misawa H, Oguchi K, Kadoi N, Fujino N, et al. Noninvasive Doppler echocardiographic evaluation of shunt flow dynamics in the ductus arteriosus. Circulation 1987; 75: 1146-53.

13 Musewe NN, Smallhorn JF, Benson LN, Burrows PE Freedom RM. Validation of doppler-derived pulmonary artery pressure in patients with ductus arteriosus under different hemodynamic states. Circulation 1987; 76: 1081-91.

14 Houston AB, Lim MK, Doia WB. Doppler flow characteristics in the assessment of pulmonary artery pressure in istics in the assessment of pulmonary artery pres

15 Halliday HL Hirschfeld S, Riggs T, Leibman J, Fanaroff A Bormuth C, et al. Respiratory distress syndrome: echocardiographic assessment of cardiovascular function and cardiographic assessment of cardiovascular function and
pulmonary vascular resistance. Pediatrics 1977; 60:

16 Evans NJ, Archer LNJ. Postnatal circulatory adaptation in healthy term and preterm neonates. Arch Dis Child 1990; 65: $24-6$.

17 Walther FJ, Benders MJ, Leighton JO. Early changes in the neonatal circulatory transition. $f$ Pediatr 1993; 123 625-31. 